Int. J. Dev. Biol. 52: 463-472 (2008)

doi: $10.1387 / \mathrm{ijdb} .072555 \mathrm{ea}$

\title{
Identification of proteins undergoing tyrosine phosphorylation during mouse sperm capacitation
}

\author{
ENID ARCELAY, ANA M. SALICIONI, EVA WERTHEIMER and PABLO E. VISCONTI* \\ Department of Veterinary and Animal Sciences, University of Massachusetts, Amherst, MA, USA
}

\begin{abstract}
Mammalian sperm are not able to fertilize immediately upon ejaculation; they become fertilization-competent after undergoing changes in the female reproductive tract collectively termed capacitation. Although it has been established that capacitation is associated with an increase in tyrosine phosphorylation, little is known about the role of this event in sperm function. In this work we used a combination of two dimensional gel electrophoresis and mass spectrometry to identify proteins that undergo tyrosine phosphorylation during capacitation. Some of the identified proteins are the mouse orthologues of human sperm proteins known to undergo tyrosine phosphorylation. Among them we identified VDAC, tubulin, PDH E1 $\beta$ chain, glutathione S-transferase, NADH dehydrogenase (ubiquinone) Fe-S protein 6, acrosin binding protein precursor (sp32), proteasome subunit alpha type $6 \mathrm{~b}$ and cytochrome b-c1 complex. In addition to previously described proteins, we identified two testis-specific aldolases as substrates for tyrosine phosphorylation. Genomic and EST analyses suggest that these aldolases are retroposons expressed exclusively in the testis, as has been reported elsewhere. Because of the importance of glycolysis for sperm function, we hypothesize that tyrosine phosphorylation of these proteins can play a role in the regulation of glycolysis during capacitation. However, neither the $\mathrm{Km}$ nor the Vmax of aldolase changed as a function of capacitation when its enzymatic activity was assayed in vitro, suggesting other levels of regulation for aldolase function.
\end{abstract}

KEY WORDS: sperm, capacitation, phosphorylation, aldolase, VDAC

\section{Introduction}

Mammalian sperm are not ready to fertilize the egg immediately after ejaculation; they need to undergo a series of biochemical and physiological changes in the female reproductive tract collectively known as capacitation (Yanagimachi, 1994). Although capacitation was discovered in the 1950s (Austin, 1951; Chang, 1951), the signaling pathways that regulate this process are not well established. Over the years, capacitation has been described using sperm functional assays and a series of endpoints have been considered to be part of this process. Among them, the ability of the sperm to fertilize the egg is the initial definition of capacitation and still the most important evidence that sperm are capacitated. More recently several authors have used two other functional correlates of capacitation. First, it is considered that only capacitated sperm can undergo an agonist-induced acrosome reaction $(A R)$. Second, because sperm hyperactivation is necessary for fertilization, this change in motility pattern is also considered part of the capacitation process. Therefore, when one attempts to understand capacitation at the molecular level, it is necessary to consider events occurring both in the head (i.e., preparation for the AR) and in the tail (i.e., motility changes).

During the last ten years, at the molecular level, work from different laboratories in several mammalian species has demonstrated that capacitation is correlated with a cAMP-dependent increase in tyrosine phosphorylation (Visconti et al., 1995a; Leclerc et al., 1996; Galantino-Homer et al., 1997; Kulanand and Shivaji, 2001). Most of these studies are focused on determining how these posttranslational changes are regulated by different compounds in the capacitation medium known to be essential for capacitation (Salicioni et al., 2007). However, little is known about the role of the proteins that undergo the capacitation-associated increase in tyrosine phosphorylation. Recent work in humans, hamster and boar has started to identify some of the proteins that

Abbreviations used in this paper: EST, expressed sequence tag; pdh, pyruvate dehydrogenase; VDAC, voltage-dependent anion channel.

\footnotetext{
*Address correspondence to: Pablo E. Visconti. Department of Veterinary and Animal Sciences, University of Massachusetts, Amherst, MA, USA. Tel: +1-413-545-5565. Fax: +1-413-545-6326. e-mail: pvisconti@vasci.umass.edu
}

Published online: 24th June 2008 
serve as substrates for tyrosine phosphorylation. The use of 2dimensional (2D) gel electrophoresis followed by tandem mass spectrometry (MS/MS) provides a comprehensive approach to the analysis of proteins involved in cell signaling (Blomberg, 1997). Specifically, changes in tyrosine phosphorylation can be monitored using 2D gel electrophoresis followed by Western blot analysis with anti- phosphotyrosine ( $\alpha$ PY) antibodies (NaabyHansen et al., 1997; Ficarro et al., 2003). Proteins that undergo changes in tyrosine phosphorylation during cellular processes can be then isolated from a complementary gel and sequenced by MS/MS. In the present study, we have used this approach to identify sperm proteins that undergo tyrosine phosphorylation during mouse sperm capacitation. Our findings are consistent with the ones obtained for human sperm (Ficarro et al., 2003). Similar to that analysis, we have found that in mouse sperm, tubulin, VDAC, PDHE1 $\beta$ chain, glutathione S-transferase, NADH dehydrogenase (ubiquinone) Fe-S protein 6 , acrosin binding protein precursor, proteasome subunit alpha type $6 \mathrm{~b}$, and cytochrome b-c1 complex are phosphorylated in tyrosine residues. Interestingly, among the proteins phosphorylated on tyrosine residues we have identified two recently described testis-specific aldolases (Vemuganti et al., 2007). Aldolase is the fourth enzyme of glycolysis; in mouse sperm, this metabolic process is the main pathway for ATP production as was demonstrated using null mutants of other glycolytic enzymes (Miki et al., 2004). Because capacitation is correlated with hyperactivation, we hypothesize that tyrosine phosphorylation of aldolase during sperm capacitation could be involved in the regulation of the glycolytic pathway during this process. In addition to the localization of aldolase in the sperm principal piece, similar to hexokinase, aldolase was also found in the sperm anterior head suggesting that glycolysis could

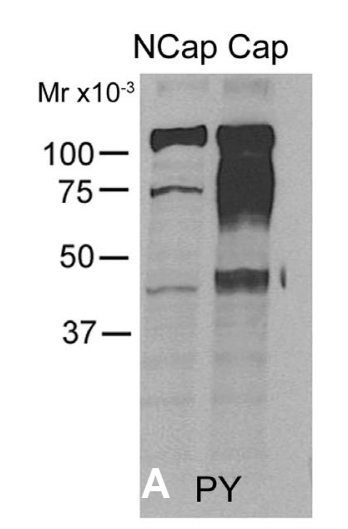

pl 3

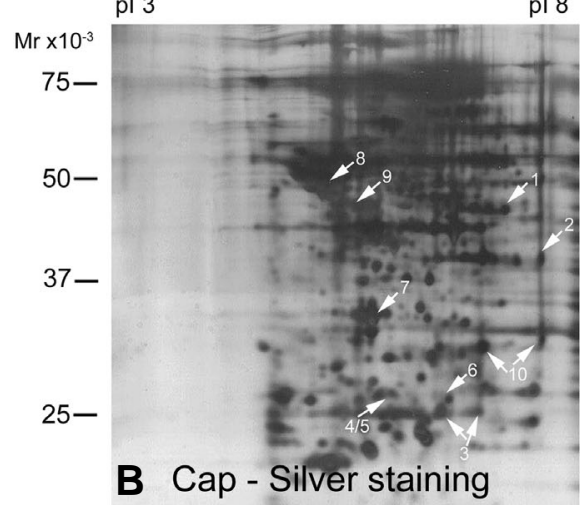

pl 3

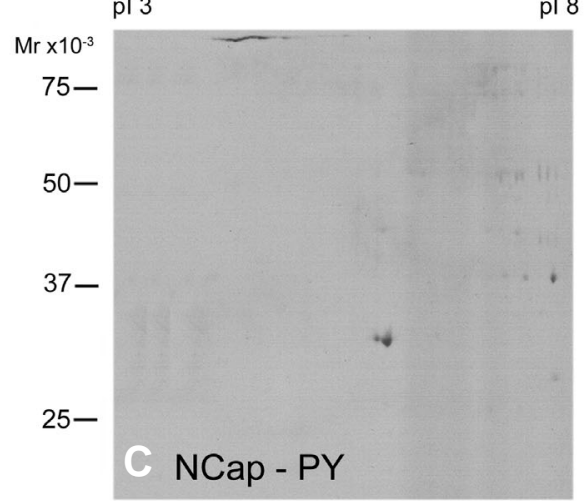

pl 8

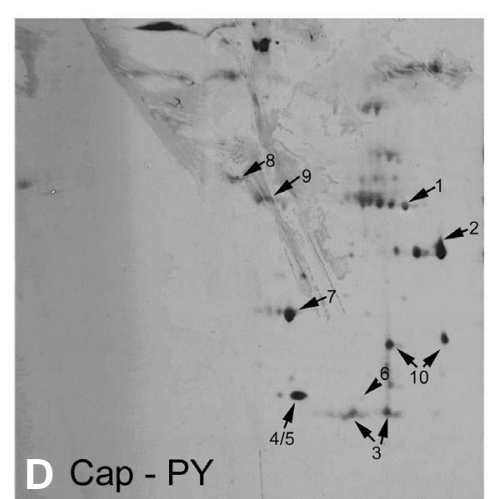

have additional functions during the preparation of the sperm for the acrosome reaction.

\section{Results}

\section{Characterization of proteins that undergo tyrosine phospho- rylation during capacitation}

To identify those proteins that undergo tyrosine phosphorylation upon capacitation, mouse sperm were incubated for $90 \mathrm{~min}$. under conditions that support $\left(+\beta \mathrm{CD},+\mathrm{NaHCO}_{3}\right)$ or not $(-\beta \mathrm{CD}$,$\mathrm{NaHCO}_{3}$ ) capacitation. Aliquots of each treatment were extracted in sample buffer and analyzed by Western blot using $\alpha$ PY antibodies (Fig. 1A). As expected, in conditions that support capacitation, an increase in protein tyrosine phosphorylation was observed. Samples from each treatment were extracted with Celis buffer and separated using 2D PAGE. For each experimental condition (NCap and Cap), 2 gels were run in parallel; one series of gels were stained with silver, while the other was transferred and probed with $\alpha$ PY. Analysis for capacitated sperm is shown in Fig. 1B,D; NCap samples probed in parallel using $\alpha$ PY served as controls (Fig. 1C. Both the silver stained gel and the Western blot were scanned and compared. Several protein spots showing $\alpha$ PY staining were excised, digested, sequenced by MS/ MS (Table I) and the predicted localization of each spot is shown in Fig. 1B,D.

Among the mouse proteins identified in this search, VDAC, glutathione S-transferase, proacrosin binding protein (sp32), pyruvate dehydrogenase (E1 beta subunit), tubulin, NADH dehydrogenase (ubiquinone) and the proteasome subunit alpha type 6 were previously detected as substrates for tyrosine phosphorylation in human sperm undergoing capacitation (Ficarro et al., 2003). Interestingly, two of the proteins that have not been yet described as tyrosine phosphorylated substrates were testisspecific isoforms of the aldolase I family recently cloned (Vemuganti et al., 2007). To confirm these findings and analyze the localization of some of the identified proteins, three of the sequenced proteins including the aldolase

Fig. 1. Analysis of the capacitation-associated increase in protein tyrosine phosphorylation by 2-D gels. Mouse sperm were incubated for 90 min in media that do not support (minus 2-OH-p- $\beta C D$, minus $\mathrm{HCO}_{3}{ }^{-}$) or support capacitation (plus 2-OH-p- $\beta C D$, plus $\mathrm{HCO}_{3}^{-}$). After this incubation period, aliquots from each condition were extracted either with SDS sample buffer for monodimensional $\alpha-p Y$ Western blot (A) or with Celis buffer for 2D PAGE analysis (B,C,D). 2D gels were then developed by $\alpha-p Y$ Western blots $(\mathbf{A}, \mathbf{C}, \mathbf{D})$ or with silver stain (B). 2D images from capacitated sperm were overlaid using AdobePhotoshop and the silver stained proteins that exhibited tyrosine phosphorylation (shown by black arrows panel (D) were cored (shown by white arrows in panel $(B)$ and sequenced by MS/MS. The following proteins were identified: 1,2, Alodart1, Aldoart2; 3, glutathione S-transferase; 4, NADH dehydrogenase (Ubiquinone); 5, acrosin binding protein (sp32); 6 , proteasome subunit alpha type $6 b ; 7, P D H \beta ; 8$, tubulin $\beta$; 9, cytochrome b-c1 complex subunit 1; 10, VDAC, numbered in the same order as in Table 1. 
isoforms were further analyzed using commercial antibodies. Antibodies against aldolase from rabbit muscle, anti-pyruvate dehydrogenase $\mathrm{E} 1 \beta$ (PDH $\beta$ ) chain and anti-voltage dependent anion channel (VDAC) were used to probe Western blots of total mouse sperm extracts (Fig. 2). Each of these antibodies recognized proteins at the appropriate molecular weight. As expected from our two dimensional sequencing as well as from the recently published work from Vemuganti et al. (Vemuganti et al., 2007), anti-aldolase antibodies recognized the shorter ( $40 \mathrm{kDa})$ and longer ( $50 \mathrm{kDa})$ sperm aldolase isoforms. Similarly, the anti-VDAC antibody recognized two proteins of similar molecular weights, implying that more than one VDAC is present in sperm as suggested previously (Hinsch et al., 2001; Hinsch et al., 2004); these molecular weights corresponded to the excised spots from the 2D gels. To further confirm this finding, aliquots of capacitated sperm protein extracts were analyzed by 2D PAGE Western blots using anti$\mathrm{PY}$, anti-aldolase, anti-PDH $\beta$ and anti-VDAC antibodies. These Western blots show that in addition to the different molecular weight, both aldolase isoforms are separated as a trail of proteins depicting a series of isoelectric points. Similarly, PDHb and the two VDAC spots were confirmed (Fig. 3 C,D). These Western blots show that, in addition to the different molecular weight, both aldolase isoforms are separated as a trail of proteins depicting a series of isoelectric points. In each case, the arrows indicate the sequenced spots as shown in Fig. 3B. Similarly, $\mathrm{PDHb}$ and the two VDAC spots were confirmed (Fig. 3C,D).

The localization of these proteins was analyzed by immunofluorescence. As expected, VDAC and PDH $\beta$ were found to be present in the midpiece where the mitochondria reside, while aldolase was found in the principal piece, the sperm cell compartment in which glycolysis has been reported. However, these three tyrosine phosphorylation substrates also localized to unexpected regions in the sperm. For example, both aldolase and VDAC were also found in the anterior head; this localization is atypical for these proteins and could be related with specific functions in the acrosomal compartments. Interestingly, both proteins are lost from the head after the acrosome reaction (Fig. 4 and data not shown).

To further analyze the sperm distribution of these proteins, the sperm were extracted in the presence of $1 \%$ Triton $\mathrm{X}-100$ for $30 \mathrm{~min}$ at $4^{\circ} \mathrm{C}$ and the solubility of aldolase, PDH $\beta$ and VDAC analyzed by Western blot. Interestingly, these three proteins distribute in both Triton X-100 soluble and insoluble fractions, and their distribution does not appear to change during capacita-

Fig. 3. Antibodies against aldolase, pyruvate dehydrogenase $E 1 \beta$ chain and VDAC matched the tyrosine phosphorylated spots in capacitated mouse sperm. Mouse sperm were incubated in capacitation-supporting medium for 90 minutes. After this incubation period, proteins were extracted in Celis buffer and separated by 2 D PAGE. Parallel immunoblots were probed using $\alpha P Y$ antibodies (A), anti-aldolase (B), anti- pyruvate dehydrogenase E1 $\beta$ chain (C), and anti-VDAC (D) antibodies. Arrows with different shapes indicate the tyrosine phosphorylated spots in $(A)$ and the respective proteins in the other Western blots. Results from a representative experiment are shown.

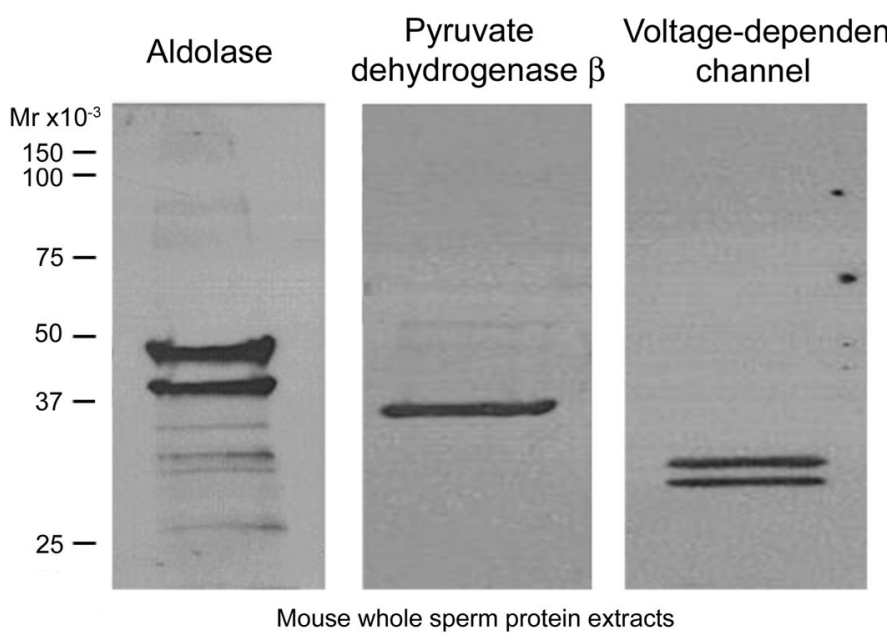

Fig. 2. Validation of anti-aldolase, anti-PDHE1 $\beta$ and anti-VDAC antibodies using mouse sperm extracts. Total mouse sperm extracts $1 \sim 2$ $\times 10^{6} \mathrm{cells}$ ) were lysed in sample buffer and separated by $10 \%$ SDS-PAGE and transferred to Inmobilon P. Western blots were performed using antialdolase, anti-pyruvate dehydrogenase E1 $\beta$ chain and anti-VDAC antibodies. Experiments shown are representative of experiments performed at least three times with similar results.

tion (Fig. 5A). In addition, anti-aldolase antibodies were used to test whether the high molecular weight aldolase isoform is also found in other tissues. Multitissue Western blots indicate that the high MW aldolase is only found in sperm and testis extracts (Fig. 5B), confirming previous observations (Vemuganti et al., 2007).

\section{Aldolase activity does not change during capacitation}

Although the capacitation-associated increase in protein tyrosine phosphorylation was described more than 10 years ago,

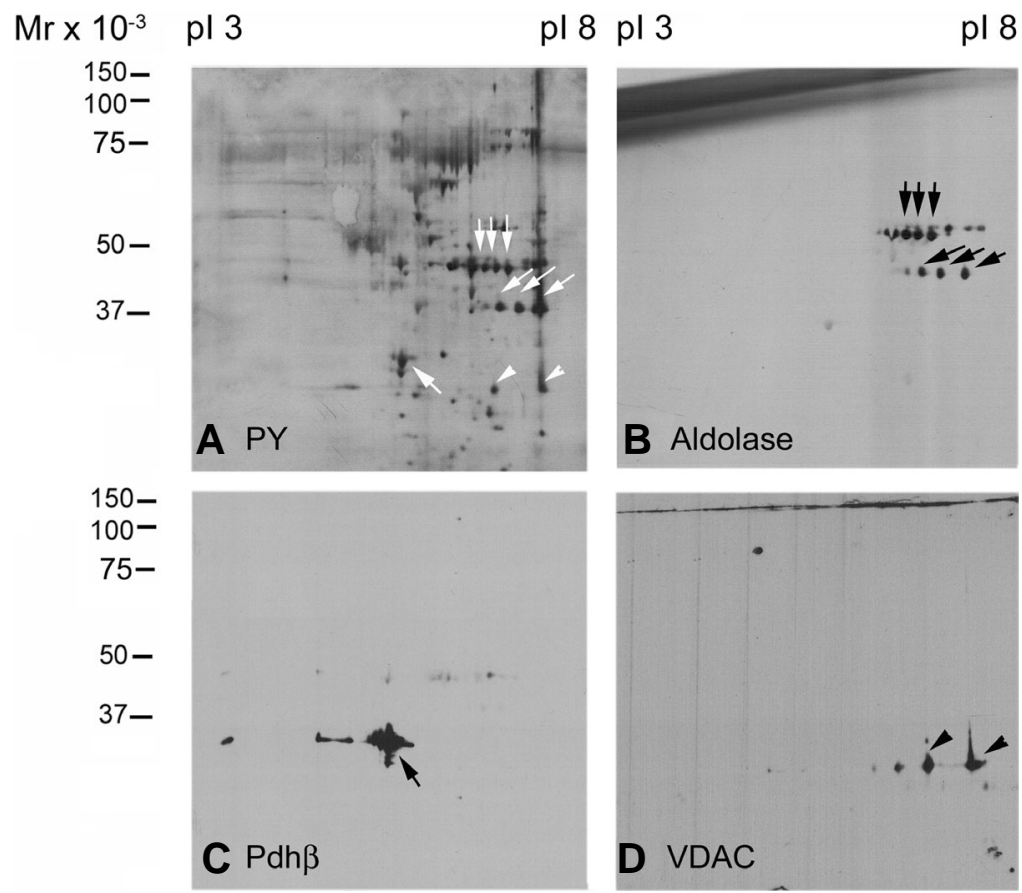



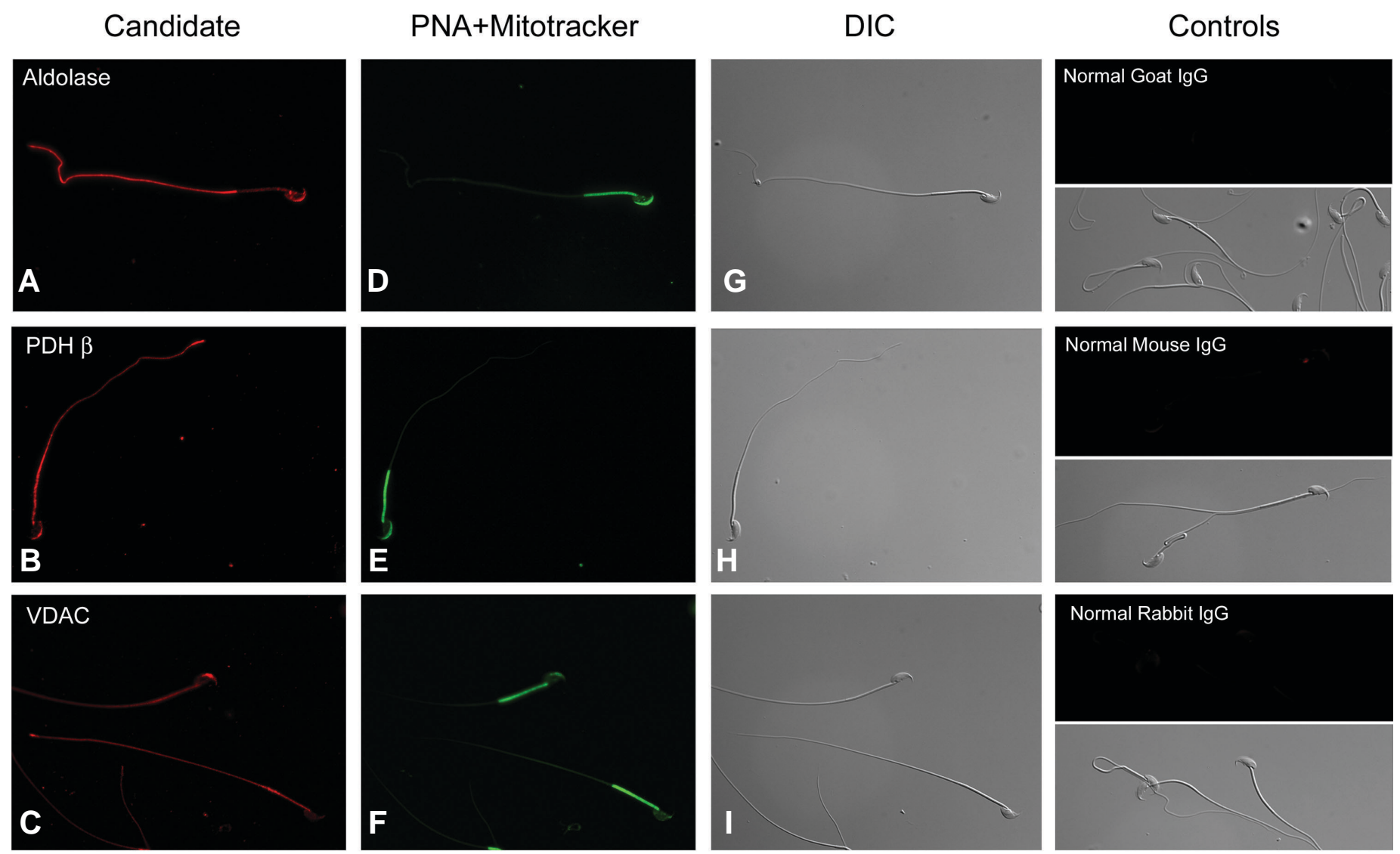

Fig. 4. Immunolocalization of phosphorylated protein targets in mouse sperm. Mouse sperm were air-dried, fixed, permeabilized and probed with antibodies for anti-aldolase (A), anti-pyruvate dehydrogenase E1 $\beta$ chain (B) and anti-VDAC (C). PNA (peanut agglutinin) stains the acrosome and mito-tracker is used as a mitochondrial marker (D-F). DIC images are shown in (G-I). As negative controls, normal IgG from goat (aldolase), mouse (dehydrogenase E1 $\beta$ chain) and rabbit (VDAC) were run in parallel. Images shown are representative of at least three repetitions with similar results.

still it is not clear how these posttranslational changes affect sperm function. Because glycolysis is the main source of energy in mouse sperm, the finding that aldolase is tyrosine phosphorylated during capacitation opens the possibility that tyrosine phosphorylation is involved in the regulation of aldolase activity and glycolysis during this process. To analyze whether this was the case, total sperm aldolase activity was measured, as well as the activity associated to soluble and particulate sperm compartments. To measure aldolase activity, a modified indirect spectrof-

A

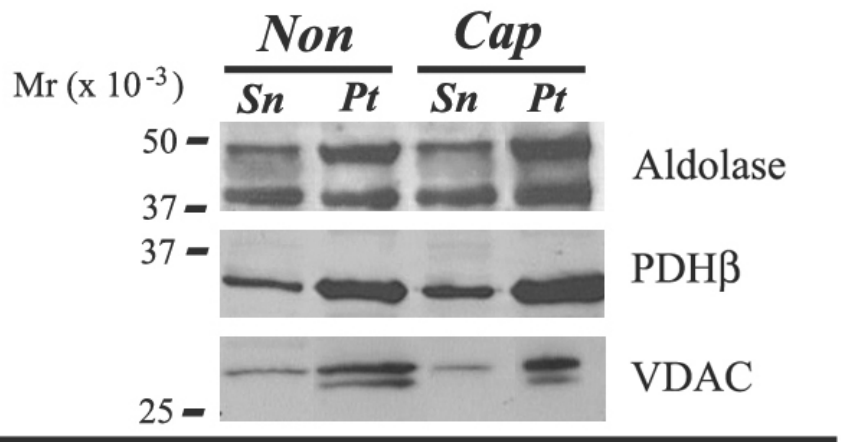

B

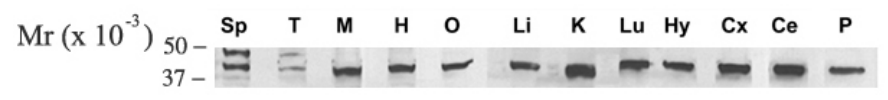

luorometric method was used taking into consideration the different emission of NADH and NAD when excited at $367 \mathrm{~nm}$ (Fig. 6A). At low concentrations of $\mathrm{NADH}$, the fluorescence using $367 / 460$ $\mathrm{nm}$ excitation/emission pair was linear (Fig. 6B). Because aldolase activity is coupled to the transformation of NADH to NAD when $\alpha$-glycero-phosphate dehydrogenase, triose phosphate isomerase $(\alpha \mathrm{GDH} / \mathrm{TPI})$ and FBP are present, the decrease in NADH was used to measure aldolase activity. Total sperm aldolase activity was linear in the conditions used in this assay (Fig.

Fig. 5. Solubility of tyrosine phosphorylation targets in Triton X 100 and Western blot analysis of mouse tissues using $\alpha$-aldolase antibodies. (A) Cauda mouse sperm were incubated in conditions that support (Cap) or not (Non) capacitation for 90 min. After this incubation the sperm were centrifuged and resuspended in buffer containing $1 \%$ Triton X 100. After $30 \mathrm{~min}$. the sperm were centrifuged and the pellet (Pt) and supernatant (Sn) analyzed by Western blots using anti-aldolase, anti$P D H \beta$ and anti-VDAC antibodies as described. The experiment shown is representative of three similar ones. (B) Immunoblot showing the presence of higher molecular weight aldolase in sperm and testis protein extracts. Ten micrograms of RIPA extracted tissues of CD1 male or female mouse were separated in $10 \%$ SDS-PAGE and immunoblotted with anti-aldolase antibody. A representative experiment of three repetitions is shown. Abbreviations: Sp(sperm); $T$ (testis); $M$ (muscle); $H$ (heart); O (ovary); Li (liver); K (kidney); Lu (lung); Hy (hypothalamus); CX (cortex); Ce (cerebellum); $P$ (pituitary). 
6C); when the cytosolic and particulate fractions were assayed, similar linearity was found (data not shown). As explained in Methods, the kinetics were evaluated in real time and the activity was calculated from the slope of NADH consumption (Fig. 6D). As shown (Fig. 6 E,F), both kinetic parameters (Km and Vmax) indicative of aldolase activity in sperm incubated in media that support (Cap) or not (NCap) capacitation did not change. Similar results were obtained when the particulate and the cytosolic fractions were assayed independently (data not shown).

\section{Discussion}

Protein phosphorylation plays a role in the regulation of intracellular processes such as transduction of extracellular signals, intracellular transport, and cell cycle progression. In sperm, capacitation is associated with a phosphorylation cascade which involves a PKA-regulated increase in protein tyrosine phosphorylation (for review see Salicioni et al., 2007)). Although the correlation between sperm capacitation and the increase in tyrosine phosphorylation has been reproduced in several mammalian species (Visconti et al., 1995a; Visconti et al., 1995b; Leclerc et al., 1996; Galantino-Homer et al., 1997; Kalab et al., 1998), the identity and functions of kinases and their targets in sperm are not well defined. An initial approach to investigate the role of phosphorylation in capacitation is to identify proteins phosphorylated during this process and to characterize the kinases involved in their phosphorylation. In this respect, the use of 2D PAGE followed by MS/MS provides a comprehensive approach to the analysis of proteins involved in cell signaling (Blomberg, 1997; Alms et al., 1999; Soskic et al., 1999; Lewis et al., 2000). Specifically, changes in tyrosine phosphorylation can be monitored using 2-D gel electrophoresis (O'Farrell, 1975, Gorg et al., 1988 ) followed by Western blot analysis with $\alpha$-PY antibodies. Proteins that undergo changes in tyrosine phosphorylation during capacitation can then be isolated from a duplicated gel stained with silver and sequenced by MS/MS. This strategy has been used before for the identification of tyrosine phosphorylated proteins in sperm from human (Naaby-Hansen et al., 1997; Ficarro et al., 2003), hamster (Kumar et al., 2006) and boar sperm (Bailey et al., 2005). In this work, a similar approach was used to start the characterization of tyrosine phosphorylated substrates in mouse sperm.

Capacitation prepares the sperm to undergo the acrosome reaction and also is associated with changes in sperm motility (e.g. hyperactivation) in a number of species (Visconti and Kopf, 1998). Therefore, it can be hypothesized that components of the sperm exocytotic and motility machinery could be found among the proteins that undergo tyrosine phosphorylation during capacitation. In particular, motility changes require elevated levels of ATP to support coordinated movements of the flagellum. The sources of ATP in the sperm are known to be compartmentalized; while oxidative phosphorylation occurs in the mid piece of the

TABLE 1

\section{PROTEINS THAT UNDERGO TYROSINE PHOSPHORYLATION UPON MOUSE SPERM CAPACITATION}

\begin{tabular}{|c|c|c|c|c|c|}
\hline & Protein & NCBI accession & MW, pl & Peptides & Sequence Coverage (\%) \\
\hline 1 & Aldolase A, retroprotein 1 & ABR88097 & $45.3,6.89$ & $\begin{array}{l}\text { K.AAQEEYIKR.A } \\
\text { K.ADDGRPFPQVIK.S } \\
\text { K.TGATASESLFISNHAY }\end{array}$ & 10.00 \\
\hline 2 & Aldolase A, retroprotein 2 & ABR88098 & $39.4,7.34$ & $\begin{array}{l}\text { K.ADDGRPFPQIIK.S } \\
\text { M.SYPYPALTPEQKK.E } \\
\text { K.YTPSNESGAAASESLFISNHAY }\end{array}$ & 14.30 \\
\hline 3 & $\begin{array}{c}\text { Glutathione S-transferase, mu 5,CRA } \\
\text { isoform }\end{array}$ & EDL01925 & $23.2,7.10$ & $\begin{array}{l}\text { K.QFSLFLGK.F } \\
\text { K.FTWFAGEK.L } \\
\text { K.SMVLGYWDIR.G } \\
\text { K.IAAFLQSDRFFK.M } \\
\text { K.LTFVDFLTYDVLDQNR.I }\end{array}$ & 30.80 \\
\hline 4 & $\begin{array}{c}\text { NADH dehydrogenase (ubiquinone) } \\
\text { Fe-S protein } 3\end{array}$ & AAH 27270 & $30.2,6.70$ & $\begin{array}{l}\text { K.DFPLTGYVELR.Y } \\
\text { R.VVAEPVELAQEFR.K } \\
\text { R.SDVTHKQLSAFGEYVAEILPK.Y }\end{array}$ & 18.63 \\
\hline 5 & $\begin{array}{l}\text { Acrosin binding protein precursor } \\
\qquad(\mathrm{sp} 32)\end{array}$ & Q3V140 & $61.1,4.89$ & $\begin{array}{l}\text { K.AEFLSFQEGDFPTK.I } \\
\text { A.QEMDEMNELYDDSWR.S }\end{array}$ & 5.92 \\
\hline 6 & Proteasome subunit alpha type $6 \mathrm{~b}$ & EDL36728 & $27.9,7.10$ & $\begin{array}{l}\text { R.HITIFSPEGR.L } \\
\text { R.LYQVEYAFK.A } \\
\text { R.ILTEAEIDAHLVALAERD }\end{array}$ & 15.93 \\
\hline 7 & Pyruvate dehydrogenase E1 beta & AAH02188 & $34.8,5.72$ & $\begin{array}{l}\text { K.EGIECEVINLR.T } \\
\text { R.IMEGPAFNFLDAPAVR.V } \\
\text { K.TYYMSAGLQPVPIVFR.G } \\
\text { K.TNHLVTVEGGWPQFGVGAEICAR.I }\end{array}$ & 18.43 \\
\hline 8 & Tubulin, beta 5 & AAH03825 & $49.7,4.69$ & $\begin{array}{l}\text { R.YLTVAAVFR.G } \\
\text { R.FPGQLNADLR.K } \\
\text { R.ISEQFTAMFR.R } \\
\text { R.AVLVDLEPTMDSVR.S } \\
\text { R.SGPFGQIFRPDNFVFGQSGAGNNWAK.G }\end{array}$ & 17.34 \\
\hline 9 & Cytochrome b-c1 complex, subunit 1 & Q9CZ13 & $52.8,5.94$ & $\begin{array}{l}\text { R.SLLTYGR.R } \\
\text { R.IQEVDAQMLR.D } \\
\text { R.RIPLAEWESR.I } \\
\text { R.VYEEDAVPGLTPCR.FK.YFYDQCPAVAGYGPIEQLPDYNR.I }\end{array}$ & 14.37 \\
\hline 10 & Voltage-dependent anion channel 2 & AAH03731 & $31.7,7.45$ & $\begin{array}{l}\text { R.SNFAVGYR.T } \\
\text { R.DIFNKGFGFGLVK.L } \\
\text { K.LTFDTTFSPNTGKK.S } \\
\text { K.VNNSSLIGVGYTQTLRPGVK.L }\end{array}$ & 21.08 \\
\hline
\end{tabular}

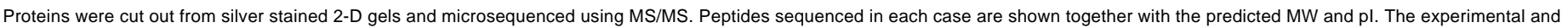

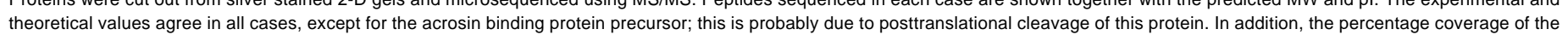
protein and the $\mathrm{NCBI}$ accession number are shown. 
Fig. 6. Aldolase activity does not change during capacitation. (A) Emission spectrum of NADH and NAD. The spectra for $1 \mathrm{mM} \beta$-NADH and 1 $m M \beta-N A D$ were obtained with an excitation wavelength of $367 \mathrm{~nm}$. The emission peak was observed at 460 $n m$; using these parameters NAD had very low fluorescent emission. (B) Fluorescence is linear with NADH when low concentrations are used. NADH was dissolved in Tris/HClbuffer at different concentrations and the fluorescence was determined as described using a 367/460 nm excitation/emission pair. A NADH concentration of $130 \mu \mathrm{M}$ was used in the aldolase enzymatic assays. (C) Aldolase activity is linear with the sperm concentration. Sperm were resuspended in Triton buffer and serial dilutions were made and assayed for aldolase activity as described. (D) $\mathrm{NADH}$ consumption vs. time after addition of sperm as a source of aldolase. The substrates for the coupled enzymatic reactions: Fructose 1,6-Di phosphate, G 3-P, $\alpha-G D H, T P I$ and NADH in Tris$\mathrm{HCl}$ buffer were placed in the same cuvette and continuous NADH fluorescence was registered before and after addition of sperm pellets. The slope of each curve was used to determine the Vo. (E) Aldolase activity in non capacitated and capacitated sperm as a function of substrate (Fructose 1,6-biphosphate) concentration. Sperm were incubated in either non capacitating or capacitating conditions and aldolase activity was assayed at different Fructose 1,6-biphosphate

A
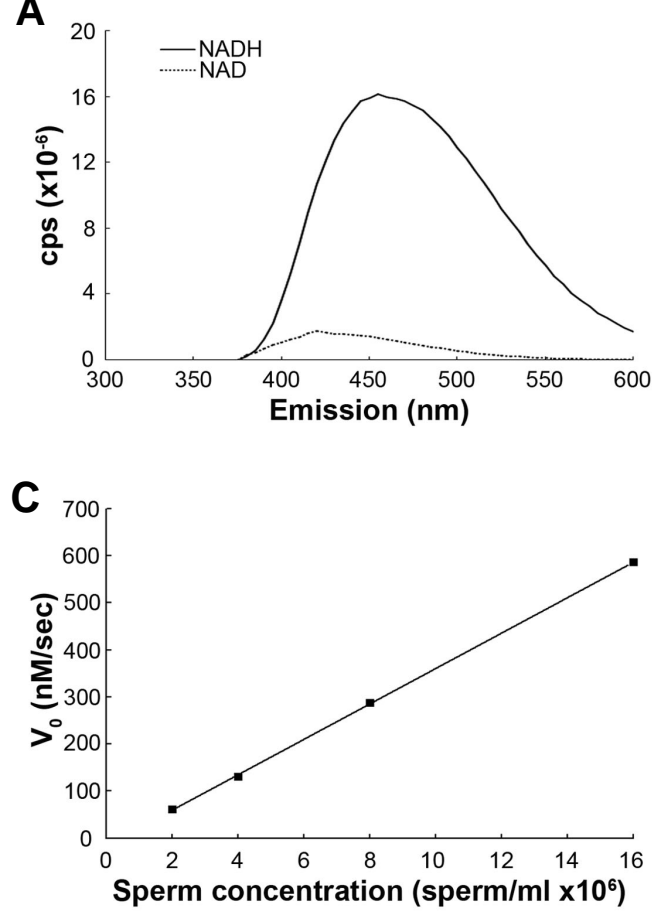

E

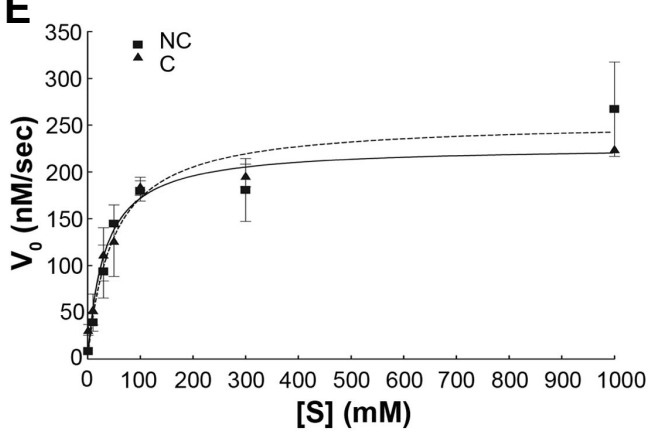

B
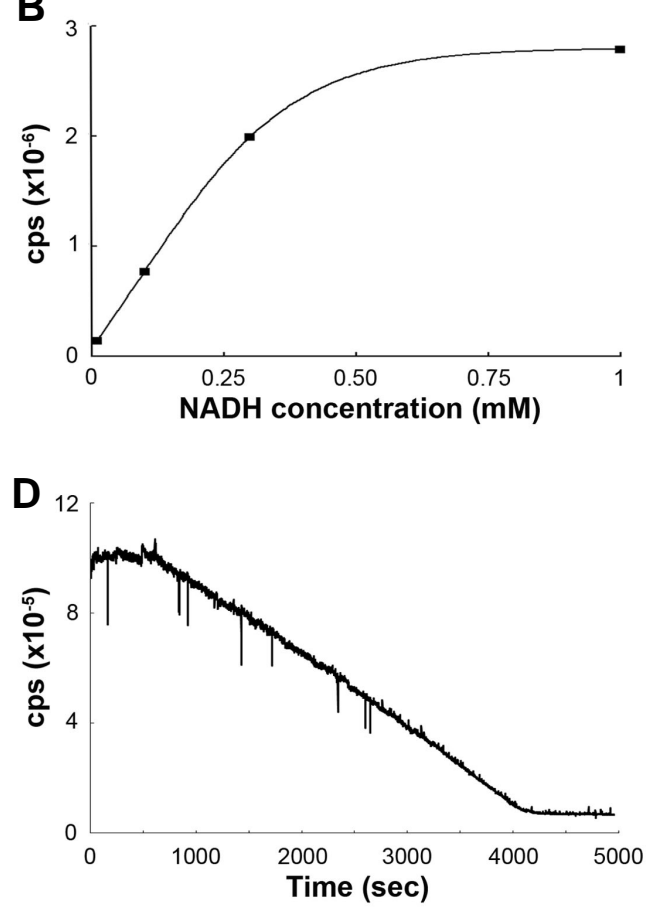

$\mathbf{F}$

\begin{tabular}{|c|c|c|}
\hline & $\mathrm{Km}$ & $\mathrm{Vm}$ \\
\hline $\begin{array}{c}\text { Non capacitated } \\
\text { sperm }\end{array}$ & $47 \pm 15$ & $254 \pm 23$ \\
\hline $\begin{array}{c}\text { Capacitated } \\
\text { sperm }\end{array}$ & $32 \pm 8$ & $227 \pm 15$ \\
\hline
\end{tabular}

concentrations. Each measurement was repeated three times in three different experiments, the values represent the mean \pm SEM. (F) Kinetic parameters for aldolase from non capacitated and capacitated sperm. The curves of Vo vs. substrate concentration shown in (E) were adjusted to the Michaelis-Menten equation: $Y=V m a x{ }^{*} X /(K m+X)$, where $X$ is the substrate concentration $(m M)$ and $Y$ is the enzyme velocity $(m M / s e c)$.

flagellum where the mitochondria are confined, glycolysis appears to be restricted to the principal piece. Although oxidative phosphorylation is more efficient than glycolysis for ATP production, recent work by Miki et al. (Miki etal., 2004) demonstrated that the absence of the sperm-specific glyceraldehyde 3-phosphate dehydrogenase -S (GAPDS) in GAPDS null mice results in a decrease of the ATP levels to almost negligible levels in their sperm. These findings suggest that at least in the mouse, the main source of ATP is through the glycolytic pathway.

Because of this relevant role of glycolysis, the identification of two testis-specific members of the aldolase family as tyrosine phosphorylated substrates is noteworthy. Fructose-1,6biphosphate aldolase (commonly referred to as aldolase) catalyzes the fourth step of the glycolysis. The mechanism involves a retro-aldol condensation reaction that cleaves the 6 carbon bi- phosphorylated fructose into two 3-carbon products: D-Glyceraldehyde 3- phosphate and dihydroxyacetone phosphate. Glycolysis has been highly conserved throughout evolution; however, in sperm, many critical glycolytic enzymes present testis-specific isoforms. These isoforms are either differentially spliced variants of somatic enzymes or they derived from independent genes. Fructose-1,6-biphosphate aldolase is an interesting example, this gene family contains three somatic members $(A / d o A, A / d o B$ and $A / d O C$ ), two testis-specific intronless genes likely evolved by retrotransposition (Aldoart1 in chromosome 4 and Aldoart2 in chromosome 12) (Vemuganti et al., 2007) and two testis-specific splicing variants of AldoA derived from the use of an extra exon in the amino-terminus region of the transcript (AldoA_v1 and AldoA_v2) (Vemuganti et al., 2007). In our study, sequencing of two tyrosine phosphorylated spots revealed peptides matching 
aldoart1 and aldoart2. Moreover, results from 2D analysis suggest that all aldolase members in sperm are tyrosine phosphorylated. This result suggests that aldolase and therefore glycolysis might be regulated by tyrosine phosphorylation in sperm. To test this hypothesis, mouse sperm were incubated in conditions that either support or not capacitation, and aldolase activity was assayed in total extracts as well as in detergent soluble and particulate fractions. In all conditions, the kinetics parameters ( $\mathrm{Km}$ and $\mathrm{Vmax}$ ) of aldolase were invariant. The lack of change in aldolase activity suggests that tyrosine phosphorylation does not play a direct role in activation of this enzyme. However, at present we cannot discard that the efficiency of the aldolase access to its substrates in vivo is not modified. Interestingly, four tyrosine phosphorylation sites have been found in somatic aldolases (www.phosphosite.org); three of these sites are conserved in the mouse aldoart1 and four of these sites are present in aldoart2. At present, the role of these phosphorylations is not known.

The source of energy for the acrosome reaction as well as other molecular processes occurring in the sperm head is not clear. The ATP needed could be produced in the mitochondria by oxidative phosphorylation and transported to the head; or alternatively, the head could have the enzymes required for glycolytic ATP production. In addition to the expected localization of aldolase in the principal piece (Krisfalusi et al., 2006; Vemuganti et al., 2007), anti-aldolase antibodies also stained the acrosomal region of mouse sperm suggesting the presence of at least one of the aldolase isoforms in this region. This is consistent with the finding of another glycolytic enzyme, hexokinase type I, in the sperm head (Visconti et al., 1996; Travis et al., 1998). Although more research is needed, localization of glycolytic enzymes in the sperm head opens the possibility that in addition to the established role in the principal piece, glycolysis could play a role in the sperm head.

In addition to the two testis-specific aldolases, eight other proteins were identified as tyrosine phosphorylation targets; from these ones, PDH $\beta$,VDAC2, glutathione S-transferase were also mapped as capacitation-associated tyrosine phosphorylation targets in human sperm (Ficarro et al., 2003), PDHE1 $\alpha$ chain in hamster sperm (Kumar et al., 2006) and the acrosin binding protein sp32 in boar sperm (Bailey et al., 2005). In the case of VDAC and PDHE $1 \beta$ chain, commercial antibodies were used to confirm tyrosine phosphorylation in the assigned proteins and to analyze their localization in sperm by immunofluorescence. In somatic cells, the voltage dependent anion channels (VDACs) were first identified in the mitochondrial outer membrane; however, VDACs have also been localized to the plasma membrane in several cell types (De Pinto et al., 2003; Wang et al., 2007). In the mitochondria, VDAC is known to function as the gate for metabolite transport from the cytosol; although it displays a rather nonspecific single channel activity, usually anionic species as phosphate, chloride, organic anions, and adenine nucleotides are transported into the mitochondria through VDAC. Recent work by Hinsch et al. (Hinsch et al., 2001; Hinsch et al., 2004) demonstrated that VDAC2 and VDAC3 are present in bovine sperm; in particular VDAC2 was shown to localize to the anterior head. Although the anti-VDAC antibodies used in the present investigation were not able to distinguish between the three VDAC isoforms, our results also indicate that in addition to the mitochondrial localization, VDAC is also localized to the acrosomal region in mouse sperm. At present, we can only speculate that tyrosine phosphorylation of VDACs may either affect the activity of these channels or their interaction with other sperm proteins.

Mammalian PDH is a tetramer consisting of two alpha and two beta subunits. Contrary to the PDH $\alpha$ that is encoded by two genes, one somatic (PDHA1) and one testis-specific (PDHA2), $\mathrm{PDH} \beta$, encoded by PDHB is common to both somatic and testicular cells (Korotchkina et al., 2006). Similar to previous findings in human sperm (Ficarro et al., 2003), PDH1beta is tyrosine phosphorylated during mouse sperm capacitation. Immunofluorescence localization of this enzyme shows the expected mid piece staining consistent with mitochondrial localization; however, this enzyme was also found in the principal piece and in the acrosomal region. These results are consistent with the finding of Fujinoki et al. (Fujinoki et al., 2004) which identified PDH E1 $\beta$ as part of the fibrous sheath in hamster sperm. Also in hamster sperm, functional studies revealed tyrosine phosphorylation of the testisspecific PDH $\alpha$ subunit of this enzymatic complex. The role of the tyrosine phosphorylation in this case appears to be coupled to an increase in the PDH activity (Kumar et al., 2006).

In summary, although work emanating from multiple laboratories is leading to a better understanding of capacitation, most of the proteins involved in this process remain to be characterized. In addition, it is important to highlight that although the increase in tyrosine phosphorylation has been correlated to sperm capacitation, it is still unclear how the changes in tyrosine phosphorylation are coupled to physiological events that occur during capacitation. The molecular identification of tyrosine kinases, phosphotyrosine phosphatases, tyrosine phosphorylation substrates, and $\mathrm{Ca}^{2+}$ channels present in mammalian sperm will certainly expand our understanding of the molecular basis of capacitation.

\section{Materials and Methods}

\section{Materials}

The following antibodies were used: anti-phosphotyrosine antibody (clone 4G10; Upstate Biotechnology, Lake Placid, NY); anti-rabbit muscle aldolase (CHEMICON International); anti-pyruvate dehydrogenase $E 1 \alpha-$ subunit (mouse $\operatorname{lgG}_{1}$, monoclonal 9H9); anti-pyruvate dehydrogenase E1 $\beta$-subunit (mouse $\lg _{1}$, monoclonal 17A5; Molecular Probes, Eugene, OR) and anti-VDAC (PA1-954 rabbit polyclonal; Affinity BioReagents, Golden, $\mathrm{CO}$ ); horseradish peroxidase-conjugated anti-mouse IgG (Jackson Immunoresearch Laboratories, West Grove, PA); horseradish peroxidase-linked anti-rabbit IgG (GE Healthcare) and horseradish peroxidase-linked anti-goat antibody (Sigma-Aldrich, Saint Louis, MO). ECL and ECLplus chemiluminescence detection kits were from Amersham Biosciences (Uppsala, Sweden). PVDF membrane was from Millipore (Bedford, MA). Alexa 555-conjugated anti-rabbit antibody, Alexa 555conjugated anti-mouse antibody, Texas Red-conjugated anti-goat antibody, Mitotracker Green and Alexa 488-labeled PNA were from Molecular Probes (Invitrogen). All other reagents were purchased from Sigma (St. Louis, MO).

\section{Preparation of mouse sperm}

Caudal epididymal sperm were collected from CD1 retired breeder males (Charles River Laboratories, Wilmington, MA) sacrificed in accordance with IACUC guidelines. Cauda epididymis from each animal were placed in $1 \mathrm{ml}$ of modified Krebs-Ringer medium (Whitten's-HEPES buffered medium) (WH) (Moore et al., 1994) containing $100 \mathrm{mM} \mathrm{NaCl}, 4.7$ $\mathrm{mM} \mathrm{KCl}, 1.2 \mathrm{mM} \mathrm{KH}_{2} \mathrm{PO}_{4}, 1.2 \mathrm{mM} \mathrm{MgSO}_{4}, 5.5 \mathrm{mM}$ glucose, $1 \mathrm{mM}$ pyruvic acid, $4.8 \mathrm{mM} \mathrm{L}(+)$-lactic acid hemicalcium salt in $20 \mathrm{mM}$ HEPES, pH 7.3. 
This medium, prepared in the absence of bovine serum albumin (BSA) and $\mathrm{NaHCO}_{3}$, does not support capacitation. Sperm released into the media during a $10 \mathrm{~min}$ time period were counted and collected by centrifugation at $800 \times \mathrm{g}$ for $10 \mathrm{~min}$ at room temperature. Sperm pellets were resuspended in $\mathrm{WH}$ medium (without $\mathrm{BSA}$ or $\mathrm{NaHCO}_{3}$ ) and then 1$2 \times 10^{6}$ sperm were incubated in $1 \mathrm{ml}$ of the medium at $37^{\circ} \mathrm{C}$ for the indicated time periods. When the sperm were incubated under capacitating conditions, WH medium was supplemented with $5 \mathrm{mg} / \mathrm{ml} \mathrm{BSA}$ plus 20 $\mathrm{mM} \mathrm{NaHCO}_{3}$. In all cases, $\mathrm{pH}$ was maintained at 7.3. In some experiments, capacitating medium contained 2-hydroxypropyl- $\beta$-cyclodextrin (2-OH-propyl- $\beta-C D)(3 \mathrm{mM}$ ) instead of BSA (Visconti et al., 1999), plus 20 mM NaHCO 3 , dbcAMP (1 mM) and IBMX (100uM). Sperm motility was checked in all the experiments and the percentage of motile sperm was over $80 \%$.

\section{SDS-PAGE and Western blots}

Phosphorylated proteins were analyzed in protein extracts from mouse sperm. Sperm pellets were washed in $1 \mathrm{ml}$ of PBS, resuspended in Laemmli sample buffer (Laemmli, 1970) without 2-mercaptoethanol and boiled for $5 \mathrm{~min}$. After centrifugation, the supernatants were saved, and 2-mercaptoethanol was added to a final concentration of $5 \%$. Samples were boiled for 5 min and subjected to SDS-PAGE using 8-10\% mini-gels; protein extracts equivalent to $1-2 \times 10^{6}$ sperm were loaded per lane. Each gel contained dual-prestained molecular weight standard (Biorad, Hercules, CA). Proteins were transferred to PVDF membranes and incubated in appropriate blocking solution for $1 \mathrm{~h}$ at the room temperature. Western blots were conducted as described (Visconti et al., 1995a) and developed using ECL chemiluminescence reagents.

\section{Two-dimensional gel-electrophoresis}

Two dimensional gel electrophoresis (2D-PAGE) was conducted as described (Jha et al., 2006); briefly, after incubation in media that support or not capacitation, sperm were centrifuged and resuspended in a modified Celis extraction/rehydration buffer $(5 \mathrm{mM}$ urea, $2 \mathrm{mM}$ thiourea, $2 \%$ CHAPS, $0.2 \%$ ampholytes pH 3-10, 50mM DTT, 0.0002\% Bromophenol blue, $1 \mathrm{mM}$ sodium orthovanadate, $10 \mathrm{mM}$ sodium fluoride, $30 \mathrm{mM} \beta$ glyceraldehyde, $2 \mathrm{mM}$ EGTA and protease inhibitors), vortexed for $2 \mathrm{~min}$ and kept on ice for $30 \mathrm{~min}$. After centrifugation at $12,000 \mathrm{xg}$ for $5 \mathrm{~min}$, extracted proteins (equivalent to $16 \times 10^{6}$ sperm per strip) were loaded passively onto IPG strips ( $\mathrm{pH} \mathrm{3-10)}$ and incubated overnight at room temperature. Isoelectric focusing (IEF) was performed using Protean IEF Cell apparatus (BioRad, Richmond, CA) starting with 15 minutes at 250 $\mathrm{V}$ and rapid increase to $4000 \mathrm{~V}$ overnight to a final 20,000 Vh. After IEF, IPG strips were equilibrated in equilibration buffer $(6 \mathrm{M}$ urea, $2 \%$ SDS, $0.05 \mathrm{M} \mathrm{Tris} / \mathrm{HCl}, 2 \%$ DTT, $20 \%$ glycerol) at room temperature for $10 \mathrm{~min}$, followed by incubation on a second equilibration buffer in which DTT was replaced with $2.5 \%$ iodoacetamide, for $10 \mathrm{~min}$ at room temperature. Second dimensional gel-electrophoresis was performed on $10 \%$ SDSPAGE gels. Proteins were transferred onto PVDF membranes and analyzed by Western blotting as described above or developed using silver stain as previously described (Ficarro et al., 2003).

\section{Image analysis of $2 \mathrm{D}$ gels}

Gel electrophoresis was performed concurrently to ensure equivalent electrophoretic conditions. Gels were stained with silver (Ficarro et al., 2003) or transferred to PVDF membrane and probed with $\alpha$ PY (clone 4G10, UBI). The silver stained gel and X-ray films (short and long exposure of ECL's) were scanned at 300 dpi using a desktop HP scanner. Digitized images were overlaid in Adobe Photoshop 7.0 using different \% of transparency. Using known "landmarks", such as hexokinase and tubulins, the silver-image was aligned with the ECL-images. After marking all reactive spots on the ECL-image with arrows, the ECL image was hidden and the arrows identified corresponding silver stained spots. These spots were then cored from the silver stained gel and submitted for mass spectrometry analysis, performed at the Proteomic Mass Spec- trometry Facility, University of Massachusetts Medical School, Worcester, MA, USA.

\section{Multi tissue western blot}

Tissues from CD1 male retired breeders, or from females, were collected and proteins were extracted using RIPA buffer $(10 \mathrm{mM}$ Tris $\mathrm{pH}$ $7.2,150 \mathrm{mM} \mathrm{NaCl}, 0.1 \%$ SDS, $1 \%$ Triton $\mathrm{X}-100,1 \%$ deoxycholate, $5 \mathrm{mM}$ EDTA, protease and phosphatase inhibitors). Tissues were resuspended in the buffer, set on ice for 30 minutes and spun down for 20 minutes. Protein concentration was assayed using the BCA (bicinchoninic acid) kit from Pierce, using bovine serum albumin (BSA) as standards. The absorbance was measured at $562 \mathrm{~nm}$ using a DYNEX plate reader and DYNEX Revelation software 4.02 (DYNEX Technologies, Worthing, UK). In each lane $10 \mu \mathrm{g}$ of total protein was loaded in an SDS-PAGE $10 \% \mathrm{gel}$. Proteins were transferred onto PVDF membranes and Western blotting was performed using anti-aldolase antibody.

\section{Indirect immunofluorescence localization}

Sperm obtained by the swim-up method in WH medium (without BSA or $\mathrm{NaHCO}_{3}$ ), were washed once, resuspended in PBS at a concentration of $1-2 \times 10^{5} \mathrm{sperm} / \mathrm{ml}$ and seeded on 8-well glass slides. After air-dried, sperm were fixed with $3.7 \%$ paraformaldehyde in PBS for $15 \mathrm{~min}$ at room temperature, washed with PBS (4 washes each for $5 \mathrm{~min}$ ) and permeabilized with $0.5 \%$ Triton $X-100$ for $5 \mathrm{~min}$. Following permeabilization, sperm were treated with $10 \%$ BSA in PBS for $1 \mathrm{~h}$ at room temperature, and then incubated either with the respective primary antibody (1:50-1:250) diluted in PBS containing $1 \%$ BSA, or with the same concentration of the corresponding normal purified IgG; incubations were carried out at $4^{\circ} \mathrm{C}$ overnight. After incubation, sperm were washed thoroughly with PBS and incubated with the corresponding Alexa 555-conjugated secondary antibody (1:200) diluted in PBS containing $1 \%$ BSA for $1 \mathrm{~h}$ at room temperature; these solutions also contained Alexa 488-conjugated PNA (1:100) for staining acrosomes, and Mitotracker (1:1000) for detecting mitochondria. Incubation with the secondary antibody was followed by 4 washes in PBS, mounting using Slow-Fade Light reagents (Molecular Probes, Eugene, OR) and observation by epifluorescence microscopy using a Zeiss Axiophot microscope (magnification 60x) (Carl Zeiss, Inc. Thornwood, NY). DIC images were taken in parallel, and served as control for sperm morphology. Negative controls using secondary antibody alone were also used to check for antibody specificity (not shown).

\section{Triton X 100 extraction}

For the separation of the Triton soluble and Triton insoluble (assumed to be the cytoskeletal) fractions, after incubation in media supportive or not of capacitation, mouse sperm samples were pelleted and resuspended in a Triton extraction buffer ( $1 \%$ Triton X-100, 1 mM EGTA, 5 mM EDTA, protease and phosphatase inhibitors in PBS) and kept on ice for $30 \mathrm{~min}$. After the incubation samples were spun at $10,000 \mathrm{~g}$ for $2 \mathrm{~min}$ and supernatant (soluble fraction) was kept on ice. The remaining pellet (nonsoluble fraction) was resuspended in Triton extraction buffer and vortexed briefly. Sample buffer was added and samples were boiled for $5 \mathrm{~min}$. After centrifugation, the supernatants were saved, and 2-mercaptoethanol was added to a final concentration of $5 \%$. Samples were boiled for $5 \mathrm{~min}$ and subjected to SDS-PAGE using $10 \%$ mini-gels as described in the SDSPAGE and Western blot methodology and developed with the antibodies indicated in the respective figure. Each lane contains equivalent sperm amounts ( $2 \times 10^{6}$ cells).

\section{Aldolase activity}

The catalytic activity of aldolase towards the substrate fructose-1,6biphosphate (FBP) was determined fluorometrically by measuring the decrease in $\beta-\mathrm{NADH}$ fluorescence over time in a coupled assay using $\alpha-$ glycerol-phosphate dehydrogenase/triose phosphate isomerase $(\alpha \mathrm{GDH} /$ TPI) and FBP as substrates (Racker, 1947, Bergmeyer, 1974). All solutions were made up in $100 \mathrm{mM}$ Tris- $\mathrm{HCl}$ buffer, $\mathrm{pH}$ 7.4. The assay 
Tyrosine phosphorylation during sperm capacitation

media contained the following: $30 \mathrm{mM}$ FBP, $130 \mathrm{nM}$ of $\beta$-NADH and 2.5 UI of $\alpha$-Glycerophosphate Dehydrogenase/Triosephosphate Isomerase Enzyme Solution (Sigma G-6755). To set the parameters for fluorescent acquisition, the emission spectra for $1 \mathrm{mM} \beta-\mathrm{NAD}$ (Sigma N-1511) and $\beta$ $\mathrm{NADH}$ (Sigma N-8129) were obtained in a 300 to $580 \mathrm{~nm}$ wavelength range, exciting from 300 to $412 \mathrm{~nm}$ wavelengths. A Jobin Yvon Horiba Fluorolog-3 fluorometer, equipped with DataMax V2.2 software was utilized for data acquisition. From the resulting spectra the $367 / 460 \mathrm{~nm}$ wavelength excitation/emission pair for $\beta$-NADH was chosen. Using this combination of wavelengths, $\beta$-NAD has no fluorescent emission (see Fig. 6 A in Results).

To determine the activity of sperm aldolase, cauda epididymal sperm was obtained as previously described and placed in either capacitating or non capacitating conditions for 1 hour. After incubation sperm aldolase Triton extraction was carried out. Briefly, sperm were sequentially centrifuged twice at $10,000 \mathrm{~g}$ for 30 second and supernatants were discarded. The pellet was resuspended in $100 \mathrm{mM}$ Tris- $\mathrm{HCl}, \mathrm{pH} \mathrm{7.4,} \mathrm{0.5 \%} \mathrm{Triton,} 1$ $\mathrm{mM}$ sodium orthovanadate, $10 \mathrm{mM}$ sodium fluoride, $30 \mathrm{mM} \beta$-glyceraldehyde, $2 \mathrm{mM}$ EGTA, protease inhibitors and incubated on ice for 30 minutes. This extract was considered to be total sperm extracts. To obtain the triton soluble and particulate fractions, the sample was spun at $10,000 \mathrm{~g}$ for 2 minutes. The remaining pellet was resuspended in extraction buffer and vortexed briefly. All the fractions were assayed; for each measurement, data was transformed from count per second (cps) to velocity, expressed in $\mathrm{nM} / \mathrm{sec}$, considering that the maximum fluorescence was obtained at $130 \mathrm{nM}$ of NADH (initial concentration) and the minimal fluorescence obtainable coincided with $0 \mathrm{nM}$ of $\beta-\mathrm{NADH}$. From the graph of concentration versus time, the initial velocity of the enzymatic reaction $\left(V_{0}\right)$ was calculated as the slope of the lineal phase of the curve, using an in-lab, custom-written program in Igor software (Wavemetrics, Inc., Lake Oswego, OR), and expressed as nM $\beta$-NADH consumed per second $(\mathrm{nM} / \mathrm{sec})$. To determine kinetic parameters $\left(\mathrm{Km}\right.$ and $\left.\mathrm{V}_{\max }\right)$ Prism4 software (GraphPad software, Inc) was used adjusting the $V_{0} v s$. substrate concentration curve to the Michaelis-Menten equation: $Y=V_{\max } X /$ $(\mathrm{Km}+\mathrm{X})$, where $X$ is the substrate concentration $(\mathrm{mM})$ and $Y$ is the enzyme velocity $(\mathrm{mM} / \mathrm{sec})$.

\section{Acknowledgements}

This study was supported by NIH HD38082 and HD44044 grants (to PEV). The authors greatly appreciate Dr Patricia Miranda from the IBYME, Buenos Aires, Argentina, for her help and advice during the initial phase of this study, and to Justyne Ogdahl at Dr Sandra Petersen's laboratory at the University of Massachusetts, for facilitating the preparation of mouse tissue protein extracts.

\section{References}

ALMS, G.R., SANZ, P., CARLSON, M. and HAYSTEAD, T.A. (1999). Reg1p targets protein phosphatase 1 to dephosphorylate hexokinase ii in saccharomyces cerevisiae: Characterizing the effects of a phosphatase subunit on the yeast proteome. Embo J18: 4157-68.

AUSTIN, C.R. (1951). Observations on the penetration of the sperm in the mammalian egg. Aust J Sci Res (B) 4: 581-96.

BAILEY, J.L., TARDIF, S., DUBE, C., BEAULIEU, M., REYES-MORENO, C., LEFIEVRE, L. and LECLERC, P. (2005). Use of phosphoproteomics to study tyrosine kinase activity in capacitating boar sperm kinase activity and capacitation. Theriogenology 63: 599-614.

BERGMEYER, H.U. (1974). Methods of enzymatic analysis. Second Edition, Vol. 1, 430. New York Academic Press, New York.

BLOMBERG, A. (1997). Osmoresponsive proteins and functional assessment strategies in saccharomyces cerevisiae. Electrophoresis 18: 1429-40.

CHANG, M.C. (1951). Fertilizing capacity of spermatozoa deposited into the fallopian tubes. Nature 168: 697-8.

DE PINTO, V., MESSinA, A., ACCARDI, R., AIEllo, R., GuARINO, F.,
TOMASELLO, M.F., TOMMASINO, M., TASCO, G., CASADIO, R., BENZ, R. et al. (2003). New functions of an old protein: The eukaryotic porin or voltage dependent anion selective channel (vdac). Ital J Biochem 52: 17-24.

FICARRO, S., CHERTIHIN, O., WESTBROOK, V.A., WHITE, F., JAYES, F., KALAB, P., MARTO, J.A., SHABANOWITZ, J., HERR, J.C., HUNT, D.F. et al. (2003). Phosphoproteome analysis of capacitated human sperm. Evidence of tyrosine phosphorylation of a kinase-anchoring protein 3 and valosin-containing protein/p97 during capacitation. J Biol Chem 278: 11579-89.

FUJINOKI, M., KAWAMURA, T., TODA, T., OHTAKE, H., ISHIMODA-TAKAGI, T., SHIMIZU, N., YAMAOKA, S. and OKUNO, M. (2004). Identification of $36 \mathrm{kda}$ phosphoprotein in fibrous sheath of hamster spermatozoa. Comp Biochem Physiol B Biochem Mol Biol137: 509-20.

GALANTINO-HOMER, H.L., VISCONTI, P.E. and KOPF, G.S. (1997). Regulation of protein tyrosine phosphorylation during bovine sperm capacitation by a cyclic adenosine 3'5'-monophosphate-dependent pathway. Biol Reprod 56: 707-19.

GORG, A., POSTEL, W. and GUNTHER, S. (1988). The current state of twodimensional electrophoresis with immobilized ph gradients. Electrophoresis 9 : 531-46.

HINSCH, K.D., ASMARINAH, HINSCH, E. and KONRAD, L. (2001). Vdac2 (porin2) expression pattern and localization in the bovine testis. Biochim Biophys Acta 1518: 329-33.

HINSCH, K.D., DE PINTO, V., AIRES, V.A., SCHNEIDER, X., MESSINA, A. and HINSCH, E. (2004). Voltage-dependent anion-selective channels vdac2 and vdac3 are abundant proteins in bovine outer dense fibers, a cytoskeletal component of the sperm flagellum. J Biol Chem 279: 15281-8.

JHA, K.N., SALICIONI, A.M., ARCELAY, E., CHERTIHIN, O., KUMARI, S., HERR, J.C. and VISCONTI, P.E. (2006). Evidence for the involvement of prolinedirected serine/threonine phosphorylation in sperm capacitation. Mol Hum Reprod 12: 781-9.

KALAB, P., PEKNICOVA, J., GEUSSOVA, G. and MOOS, J. (1998). Regulation of protein tyrosine phosphorylation in boar sperm through a camp-dependent pathway. Mol Reprod Dev 51: 304-14.

KOROTCHKINA, L.G., SIDHU, S. and PATEL, M.S. (2006). Characterization of testis-specific isoenzyme of human pyruvate dehydrogenase. J Biol Chem 281 : 9688-96.

KRISFALUSI, M., MIKI, K., MAGYAR, P.L. and O'BRIEN, D.A. (2006). Multiple glycolytic enzymes are tightly bound to the fibrous sheath of mouse spermatozoa. Biol Reprod 75: 270-8.

KULANAND, J. and SHIVAJI, S. (2001). Capacitation-associated changes in protein tyrosine phosphorylation, hyperactivation and acrosome reaction in hamster spermatozoa. Andrologia 33: 95-104.

KUMAR, V., RANGARAJ, N. and SHIVAJI, S. (2006). Activity of pyruvate dehydrogenase a (pdha) in hamster spermatozoa correlates positively with hyperactivation and is associated with sperm capacitation. Biol Reprod75: 76777.

LAEMMLI, U.K. (1970). Cleavage of structural proteins during the assembly of the head of bacteriophage t4. Nature 227: 680-5.

LECLERC, P., DE LAMIRANDE, E. and GAGNON, C. (1996). Cyclic adenosine 3',5'monophosphate-dependent regulation of protein tyrosine phosphorylation in relation to human sperm capacitation and motility. Biol Reprod 55: 684-92.

LEWIS, T.S., HUNT, J.B., AVELINE, L.D., JONSCHER, K.R., LOUIE, D.F., YEH, J.M., NAHREINI, T.S., RESING, K.A. and AHN, N.G. (2000). Identification of novel map kinase pathway signaling targets by functional proteomics and mass spectrometry. Mol Cel/6: 1343-54.

MIKI, K., QU, W., GOULDING, E.H., WILLIS, W.D., BUNCH, D.O., STRADER, L.F., PERREAULT, S.D., EDDY, E.M. and O'BRIEN, D.A. (2004). Glyceraldehyde 3phosphate dehydrogenase-s, a sperm-specific glycolytic enzyme, is required for sperm motility and male fertility. Proc Natl Acad Sci USA 101: 16501-6.

MOORE, G.D., AYABE, T., VISCONTI, P.E., SCHULTZ, R.M. and KOPF, G.S. (1994). Roles of heterotrimeric and monomeric g proteins in sperm-induced activation of mouse eggs. Development 120: 3313-23.

NAABY-HANSEN, S., FLICKINGER, C.J. and HERR, J.C. (1997). Two-dimensional gel electrophoretic analysis of vectorially labeled surface proteins of human spermatozoa. Biol Reprod 56: 771-87.

O'FARRELL, P.H. (1975). High resolution two-dimensional electrophoresis of proteins. J Biol Chem 250: 4007-21. 
RACKER, E. (1947). Spectrophotometric measurement of hexokinase and phosphohexokinase activity. J. Biol. Chem. 167: 843-854.

SALICIONI, A.M., PLATT, M.D., WERTHEIMER, E.V., ARCELAY, E., ALLAIRE, A., SOSNIK, J. and VISCONTI, P.E. (2007). Signalling pathways involved in sperm capacitation. Soc Reprod Fertil Supp/65: 245-59.

SOSKIC, V., GORLACH, M., POZNANOVIC, S., BOEHMER, F.D. and GODOVACZIMMERMANN, J. (1999). Functional proteomics analysis of signal transduction pathways of the platelet-derived growth factor beta receptor. Biochemistry 38: 1757-64.

TRAVIS, A.J., FOSTER, J.A., ROSENBAUM, N.A., VISCONTI, P.E., GERTON, G.L., KOPF, G.S. and MOSS, S.B. (1998). Targeting of a germ cell-specific type 1 hexokinase lacking a porin- binding domain to the mitochondria as well as to the head and fibrous sheath of murine spermatozoa. Mol Biol Cel/9: 263-76.

VEMUGANTI, S.A., BELL, T.A., SCARLETT, C.O., PARKER, C.E., PARDOMANUEL DE VILLENA, F. and O'BRIEN D, A. (2007). Three male germlinespecific aldolase a isozymes are generated by alternative splicing and retrotransposition. Dev Bio/309: 18-31.

VISCONTI, P.E. and KOPF, G.S. (1998). Regulation of protein phosphorylation during sperm capacitation. Biol Reprod 59: 1-6.

VISCONTI, P.E., MOORE, G.D., BAILEY, J.L., LECLERC, P., CONNORS, S.A., PAN, D., OLDS-CLARKE, P. and KOPF, G.S. (1995a). Capacitation of mouse spermatozoa. li. Protein tyrosine phosphorylation and capacitation are regulated by a camp-dependent pathway. Development 121: 1139-50.

VISCONTI, P.E., MOORE, G.D., BAILEY, J.L., LECLERC, P., CONNORS, S.A., PAN, D., OLDS-CLARKE, P. and KOPF, G.S. (1995b). Capacitation of mouse spermatozoa. li. Protein tyrosine phosphorylation and capacitation are regulated by a camp-dependent pathway. Development 121: 1139-50.

VISCONTI, P.E., OLDS-CLARKE, P., MOSS, S.B., KALAB, P., TRAVIS, A.J., DE LAS HERAS, M. and KOPF, G.S. (1996). Properties and localization of a tyrosine phosphorylated form of hexokinase in mouse sperm. Mol Reprod Dev 43: 82-93.

VISCONTI, P.E., STEWART-SAVAGE, J., BLASCO, A., BATTAGLIA, L., MIRANDA, P., KOPF, G.S. and TEZON, J.G. (1999). Roles of bicarbonate, camp, and protein tyrosine phosphorylation on capacitation and the spontaneous acrosome reaction of hamster sperm. Biol Reprod 61: 76-84.

WANG, Z.J., ZHANG, W., WU, H.F. and SUI, Y.G. (2007). [voltage-dependent anion channels (vdac) on human sperm membrane]. Zhonghua Nan Ke Xue13: 498-501.

YANAGIMACHI, R. (1994). Mammalian fertilization. In The physiology of reproduction, vol. 1 (ed. KNOBIL, E. and NEILL, J. D.). Raven Press, Ltd., New York, pp.189-317.

\section{Related, previously published Int. J. Dev. Biol. articles}

See our recent Special Issue Developmental Biology in Poland edited by Tarkowski, Maleszewski and Kloc at: http://www.ijdb.ehu.es/web/contents.php?vol=52\&issue=2-3

See our recent Special Issue Ear Development edited by Fernando Giraldez and Bernd Fritzsch at: http://www.ijdb.ehu.es/web/contents.php?vol=51\&issue=6-7

Glycobiology of fertilization in the pig

Edda Töpfer-Petersen, Mahnaz Ekhlasi-Hundrieser and Miroslava Tsolova Int. J. Dev. Biol. (2008) 52: 717-736

CDK4 activity in mouse embryos expressing a single D-type cyclin Maria A. Ciemerych, Qunyan Yu, Katarzyna Szczepanska and Piotr Sicinski Int. J. Dev. Biol. (2008) 52: 299-305

Aard is specifically up-regulated in Sertoli cells during mouse testis differentiation Terje Svingen, Annemiek Beverdam, Pali Verma, Dagmar Wilhelm and Peter Koopman Int. J. Dev. Biol. (2007) 51: 255-258

Ca2+-independent protein kinase $\mathrm{C}$ signalling in mouse eggs during the early phases of fertilization.

Carla Tatone, Simona Delle Monache, Antonella Francione, Luisa Gioia, Barbara Barboni and Rosella Colonna

Int. J. Dev. Biol. (2003) 47: 327-333

Fertilization triggers activation of Fyn kinase in the zebrafish egg. W Wu and W H Kinsey Int. J. Dev. Biol. (2000) 44: 837-841

Tissue-specific distribution and variation of the channel-forming protein ductin during development of Drosophila melanogaster.

$\mathrm{J}$ Bohrmann and A Bonafede Int. J. Dev. Biol. (2000) 44: 883-890

Receptor protein-tyrosine phosphatase signalling in development. J den Hertog, C Blanchetot, A Buist, J Overvoorde, A van der Sar and L G Tertoolen

Int. J. Dev. Biol. (1999) 43: 723-733

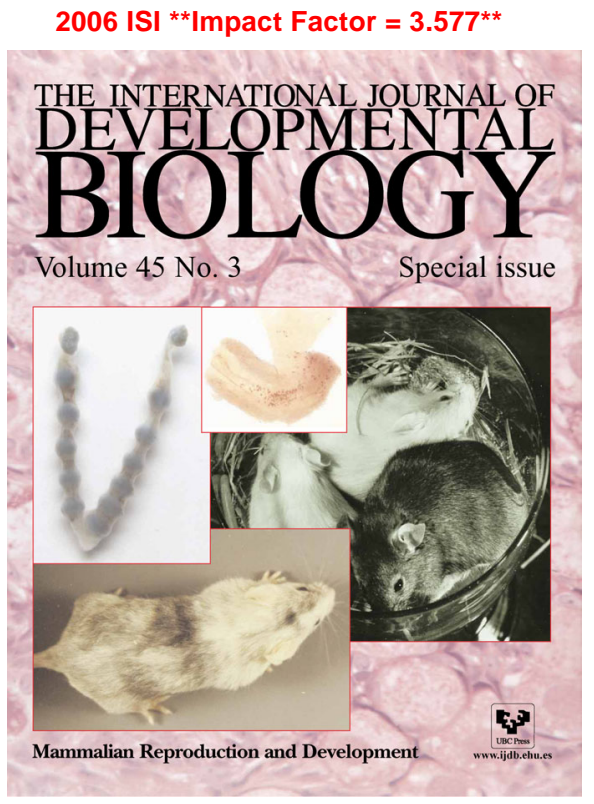

